\title{
Bisexual and Invisible Memory: Gendered Design History of Domestic Sewing Machine, 1850-1950
}

Sewing machine, the rock star at the era of worshipping on industrial power, was regarded as "one of amazement and astonishment at technical virtuosity" (Hounshell 1984: 67). No matter how sophisticated it was as a scientific advancement, it's agreeable that sewing machine is the designed artifact after all. Sewing machine, however as the one of most common domestic appliances, was barely invisible in design history due to a couple of reasons. Design history and gender were the dualspindle here: firstly, with the discourse of design history, I will sketch the trace of sewing machine in its design development and aesthetic innovation of style, the shape, function, size, material, style, and ornament; secondly, with the category of gender, I will investigate women consumers' cultural identity and modernity experience on home sewing. Why did the sewing machine appear so minimally in the text of design history?

Who designed the sewing machine and decided the style? Why did the sewing machines become similar among the four dominant manufactures? What is the relation among home sewing and its machine? How and why did the sewing machine from the factory equipment become more emotionally and physically acceptable to the family members? Exploration to these inquiring is constructed my arguments based on both technological and sentimental contexts.

keywords sewing machine, gender, design history, memory

\section{Introduction}

Gender is unavoidably working through the history of sewing machine design, from its technological invention to the cultural popularization, from its superficial feminine appearance to the essential complicated mechanism. Male inventor or engineer were in charge of its production, while the costumers went to women. Sewing machine as the material artifact was an aggregation on which women played their gender performance, including the mother's love to children, femininity charming to husband, housewife's industriousness to family, as well as proficient skill and confidence to social community.

Invisibility of sewing machine in design history was caused by multiple explanations. One of them may go to its major female operator, who was the marginal gender identity, absented in the historic and realistic contents. The history of domestic sewing machine can be traced back to the mid-19th century, however only was presented as the technological invention within the Industrial Revolution or American System of Manufacturing only by description of the patent information (Cooper 1976; Bourne 1895), whilst being lost of the alive cultural stories. This paper will provide a multilevel perspective of sewing machine, as the designed artifact with which embedded the 
contextual interpretations, both from the hard (design developments) and soft (gender/memory) views.

Studies on sewing machine have thrived since the 1960s, uncountable amount of sources were concerned to my paper writing. Although adequate references on sewing machine existed, design historical research combined technological standpoint, stories of manufactures, cultural studies from material and visual, and gendered memories relevant were insufficient. Perceiving sewing machines with gender is a cord throughout this paper. It's absorbing to find out that two gender identities as the two unique sexual temperaments were compounding: designed and manufactured by men, while consumed and operated by women; its material and structure were marked with obviously muscular features, while the decoration on its surface and the curved shape were typically feminine.

\section{Road to the Domesticity: Evolution of Sewing Machine Design}

The earlier design evolution of sewing machine, more specifically, the domestic sewing machine, was the transformation from factory-like to the family taste, from industrial coldness to the aesthetic attractiveness, from the large to the miniature, from open structure to the concealment, from device in workshop to the furniture in home, from complexity to the easy-to-use, from public sphere to the private and individual; in short, from masculinity to the femininity, which were the results of the changing from the men's standpoint at which the beginning of invention and manufacture, to the women's endpoint where the happening of consumption, operation, creation, service with the help of domestic sewing machine.

In 1854, Wheeler and Wilson introduced the first sewing machine for domesticity which had been thought as the technological miracle dramatically changing the actuality of low production in fabric industry. Design development of the sewing machines, was haunted by its advanced in technology and sophistication in structure, moreover the patent war persisting from 1850 s to 1870 s, especially the aesthetic refinement.

Unconsciousness of design earlier in the mid of 1850s, spotlight of sewing machine development was marketing-oriented, defensive for the patents along with the anxiety for expanding oversea market, and design was more or less disregarded. Of the sewing machine, consequently, all the details with design relevance, including the shape, color, structure, material, decoration, style, left little mark in neither text nor image archive.

\section{Beyond the Patent War: Refine for the Family}

The essential parts of the early sewing machine had been set up by the four American manufactures, Wheeler \& Wilson(1850), Singer(1851), Grover \& Baker(1851) and Willcox \& Gibbs(1857), from the late of 1840 s to 1850 s. They were guiding the fundamental structure and its mechanism of domestic modern sewing machine industry. (Davies 1976: 5-12; Hounshell 1984: 67) Before the 1850s, the function of sewing machines by the leading four manufactures was defective.

The pioneer of design reform on individual sewing machine after the patent war, started from the "softening strategy" on its appearance, reducing its size, decreasing the weight, simplifying the structure, and adding decoration to the surface. The prototype of domestic sewing machine in the last half of $19^{\text {th }}$ century was created by the series of Singer's New Family. 
New Family which was initially launched in 1865, the name itself had unveiled the Singer's ambition of the market of home sewing machine. From 1865 to 1882, the 'New Family' had been sold to almost developed countries in the world, the distribution in total was up to four millions. From the New Family by Singer, it's easy to tell the explicitly intention of the male inventors, that sewing machine was exclusively designed for female consumers. Curved shape of bed plate with the wood case bottom, intense feminine gamosepalous patterns with bold golden color fulfilled the arm and face plate, were matching the golden decorated logo plate in front of the arm stand.

However, due to its complicated mechanism and craft, the price was far beyond the scope which ordinary family can afford. Redesigning women-friendly sewing machine, reducing its cost and providing options of payment, were three valid approaches to assist manufacturers expanding its market occupancy. Moreover, sewing machine was becoming a status symbol with dual meanings of financial and lifestyle.

\section{Redesign for the New Women: Become Furniture and Portable}

Cultural prejudice was another obstruction the manufactures urged to remove to attract women consumers. Sewing machine, in its cultural context as well as in the artifact history, was bound with the ideas of masculinity and anti-domestic. The relation between women and sewing machine was mutually exclusive for two reasons, low or no income from wage labor, and sketchy know-how and deficient skill at using or mending machines. Contradictorily, women, especially housewives without salary were the targeted consumers.

Industrialization of public world and modernization of domestic life occurred at the almost same time "In the collision, the machine was adapted to its new domestic setting" (Douglas 1982:20) Decoration and soft curve as the exterior of home sewing machine used to neutralize its masculinity as machine. Furthermore, middle class family in Victorian era was learnt to cover the exposed parts of sewing machine into a decent case which was more fitted to their taste on home interior.

Design the sewing machine to one piece of furniture which was multifunctional and conformed to home environment; yet, making machine more portable and personal which suited to the identity of modern women with the ability of changing space and independence. Small size, lighter weight, elegant form, and decorated style, almost covered all the attractive attributes of family sewing machine since the early of 1860 s.

Portable electric sewing machine was the compact version. When sewing finished, the whole machine could be completely encased in a fashionable bent wood locking case with modest handle and ready to go. Well-designed portable sewing machine similar to the jewel case or musical box, perfectly matched the fashion-dressed lady to be involved in social life. Procession of a portable sewing machine could be favorable to picture an icon of new women who were self-reliant, socially connected, in the fashion, dress-for-identity.

\section{Invisible Memory and Pleasure Sewing}

Artifacts that people used in daily told the stories about who they were and how they lived. As the sewing machine, however, what we just discussed about its masculinity in almost everywhere, its rough sense of the metallic, dull coloring, uncased structure, complicated mechanism and the male creators. It's ironically to say though that the 
deep-seated emotional bond between sewing machine and family life was memorized largely by women. Sewing is a robust action which depending on its purpose which means there was twofold way to interpret why women love domestic sewing work. For the family sake, it's mainly about finance and service. For themselves, women involved in sewing routine passionately for hunting pleasure, presenting their taste and creativity, more importantly, to perform their gender identity with the behavior of concentrated sewing as good wife and innovated customized clothes as the rebellion to traditional stereotype of femininity.

Nancy P. Fernandez (1999: 157-158) employed the word of "anxiety" accurately presenting the tension between the new era of Industrialization and female homeworker. Sought to smooth it, advertiser played the role of "mediator" by creating a modern consumer of female gender and middle class. Buying the sewing machine as the first modern home equipment to represented as the middle class and new identity as modern consumer. Obviously gendered ideology had appeared the meanings of sewing machine to women 'The Queen of Inventions' (Godey's Lady's Book 1860), 'Best boon to women in the nineteenth century' (New York Times 1865, as cited in Connolly 1999: 24), 'Angel of the house', 'Iron needle women'. (Grover \& Baker 1862)

In one word, promoters created a perfect family picture consisting of love, happiness, comfort, modernity, independence, of course, with the advent of the sewing machine.

Desire for uniqueness revealed women's yearning for fresh identity corresponding with the modernity. Dress fashionably and uniquely is the most effective way, luckily for the women in the $20^{\text {th }}$ Century, domestic sewing machine made their dream come true. Identity illusion with the passion and desire embroidered the fabulous picture scroll of sewing machine in the early $20^{\text {th }}$ century. Women chose to sewing not for serving others any more, but for pleasing themselves. After the 1930s, women consumers to sewing machine were shattering the rooted norm of the truly womanhood that woman's reasonable performance was to playing roles only for family and home. Their proficient skills about sewing had been transformed from the seamstress to tactful consumers, they begun to become one of the parts in public life by the discourse on home-made fashions.

\section{Conclusion}

Sewing machine was concerned as a technological invention rather than a designed artifact in its long history. Pursuing the profit not the fame in its aesthetics innovation, manufactures paid large focus on its patent competition, mechanism enhancement and marketing promotion. Sewing machines were produced nearly all by men in which gender chunk was a virtually unbearable. The tone of masculinity steered the route of sewing machine development. Limited to its technological obstruction and patent competition, the progression and variety of design of sewing machine was severely delayed.

Design changed the relationship between sewing machine and its female operator. Firstly, redesigning its size, simplifying the structure, improving its mechanism, softening its appearance, adding some styled elements which learnt from the Art Nouveau, Rococo, Art Deco, and Orientalism, were applied for catering to the taste of women consumers. Then, rendering the modern attitude of homing sewing was an essential step to persuade women to choose the sewing machine both for the family and themselves.

A culture of sewing had been longstanding existed, however, the sewing machine really reduced the suffering of the inefficient, difficult and arduous stitching work. All the 
stakeholders of sewing machine industry absorbed nutrition from the sewing culture. Needles working with female family elders, always was woven into the cherishing memories to the next female generation; sewing experience alone or with female friends, were other emotional treasure in self-pride memories.

Situated at the center of sewing machine design history with gender, it's intriguing to zoom in the every detailed grid within the web of the earlier industrialization society that means a lot to women. The design history of sewing machine without her memory would be definitely faded and boring.

\section{References}

Bays, C. (2007) The encyclopedia of early American and antique sewing machines: identification and values, Paducah: Collector Books.

Beadry, M. C. (2006) Findings: the material culture of needlework and sewing, New Haven: Yale University Press.

Betts, P. (2004) The authority of everyday objects: a cultural history of west German industrial design. Berkeley: University of California Press.

Bourne, F. G. (1895) 'American sewing machines', In Depew, C. M. (ed.) One Hundred Years of American Commerce, vol. 2, New York: D. O. Hains, pp. 525-539.

Brandon, R. (2006) A capitalist romance: singer and the sewing machine, $3^{\text {nd }}$ edition, New York: Kodansha USA, Inc..

Burman, B. (1999) The culture of sewing: gender, consumption and home dressmaking, New York: Berg Publishers.

Chamberlain, M. (1995) Gender and memory: oral history and women's history, New York: St. Martins Press.

Connolly, M. (1999) 'The disappearance of the domestic sewing machine, 1890-1925,'

Winterthur Portfolio, vol. 34, no.1, pp. 31-48.

Cooper, G. R. (1976) The sewing machine: Its invention and development. Washington, DC: Smithsonian Institution Press.

Davies, R.B.(1976) Peacefully Working To Conquer The World: Singer Sewing Machines In Foreign Markets, 1854-1920. New York: Arno Press.

Douglas, D.M. (1982) 'The machine in the parlor: A dialectical analysis of the sewing machine', Journal of American Culture, vol.5, no.1, pp. 20-29.

Fernandez, N.P. (1999) 'Creating consumers: gender, class and the family sewing machine' In Burman, B. (ed.) The Culture of Sewing: Gender, Consumption and Home Dressmaking. Oxford: Berg Publishers.

Forty, A. (1986) Objects of Desire: Design and Society Since 1750. New York: Pantheon Books. Godley, A.(2006) 'Selling the sewing machine around the world: Singer's international marketing strategies, 1850-1920,' Enterprise and Society, vol. 7, no.2, pp. 266-314.

Gordon, S.A. (2004). 'Boundless possibilities: home sewing and the meanings of women's domestic work in the United States, 1890-1930,' Journal of Women's History, vol.16, no.2, pp. 68-91.

Head, C. (1982). Old sewing machines, Oxford: Osprey Publishing.

Hounshell, D. A. (1984) From the American system to mass production, 1800-1932: The development of manufacturing technology in the United States. Baltimore, Maryland: The Johns Hopkins University Press.

Mossoff, A. (2009). 'The rise and fall of the first American patent thicket: the sewing machine war of the 1850s,' Arizona Law Review, vol. 53, vol.1, pp. 165-211.

The Seams of the Leading Machines, Illustrated and Compared (1862) New York: Grover and Baker.

'The Queen of Inventions: The Sewing Machine,' (1860) Godey's Lady's Book, vol.61, no.1, pp. 77. 
